Case Report

\title{
A Rare Case Report on Suboccipital Region Benign Giant Osteoma
}

\author{
Sunil Munakomi and Binod Bhattarai \\ Department of Neurosurgery, College of Medical Sciences, P.O. Box 23, Chitwan, Nepal \\ Correspondence should be addressed to Sunil Munakomi; sunilmunakomi@gmail.com
}

Received 5 December 2015; Accepted 21 February 2016

Academic Editor: Jacqueline A. Pettersen

Copyright (C) 2016 S. Munakomi and B. Bhattarai. This is an open access article distributed under the Creative Commons Attribution License, which permits unrestricted use, distribution, and reproduction in any medium, provided the original work is properly cited.

\begin{abstract}
Herein we report a rare case of a giant suboccipital osteoma in a 55-year-old woman presenting primarily due to cosmetic issue. We discuss the management algorithm taken in the patient, highlighting excision of a potentially curable bony tumor only after ruling out its extension to the ear cavity, mastoid ear cells, transverse sinus, and the intracranial compartment.
\end{abstract}

\section{Introduction}

Osteomas in the occipital and mastoid regions are exceptionally rare with only 137 cases reported in the literature [1-3]. Asymptomatic in most of the cases, patients may present with esthetic issues or symptoms of external auditory obstruction $[1,4]$. Computed tomography is the gold standard for diagnosis [5]. The main aim of the radio imaging is to rule out invasion of the inner table of the calvarium and its intracranial extension of the lesion [1]. Complete excision in the symptomatic and giant osteomas is the therapeutic goal [4].

\section{Case Report}

A fifty-five-year-old woman from Chitwan, Nepal, visited our patient surgical outpatient clinic with a chief complaint of slowly progressive swelling at the back of her head. She had detected the swelling since her twenties. There was no history of trauma, redness, ear discharge, deafness, or similar swellings elsewhere in her body. It slowly progressed in size over time. Once it attained a massive size, she sought medical advice. There were no important past medical or surgical illnesses. Her bladder and bowel habits were normal. Examination revealed a bony and sessile swelling on the right suboccipital region and extending below the craniovertebral junction (Figure 1). The skin overlying the lesion was normal. The margin of the lesion was clearly demarcated. The cranial nerves were intact. The otoscopic examination was normal. CT scan revealed a hyperostotic spherical lesion measuring $6 \times 5 \mathrm{~cm}^{2}$ within the right suboccipital region highly suggestive of a giant osteoma (Figure 2). Because of the large size and primarily for cosmetic reasons, she was counseled for surgical excision of the lesion. The lesion proved to be a bony sessile mass extending from the lambdoid suture superiorly to $\mathrm{Cl}$ arch inferiorly (Figure 3). The lesion was excised with the assist of a Gigli saw and later chiseled (Figure 4). The bleeding from the base was controlled with the application of a bone wax. The mastoid air cells were not violated. The inner table of the bone beneath was intact (Figure 5). The postoperative period of the patient was uneventful and she was discharged on the third day. The histopathological study confirmed the compact variant of benign osteoma. The patient followed up in the OPD 2 months later. The scar was healthy and she had no new complaints. She was assured and advised for a sixmonth follow-up.

\section{Discussion}

Osteoma is a slow-growing benign mesenchymal osteoblastic tumor formed by mature bone tissue [6]. Osteomas, constituting $0.1-1 \%$ of all benign skull tumors, are extremely rare [7]. The most common site reported is the frontoethmoidal region and neighboring sinuses. Involvement of the temporal and occipital squama is extremely rare [8]. Osteomas larger 


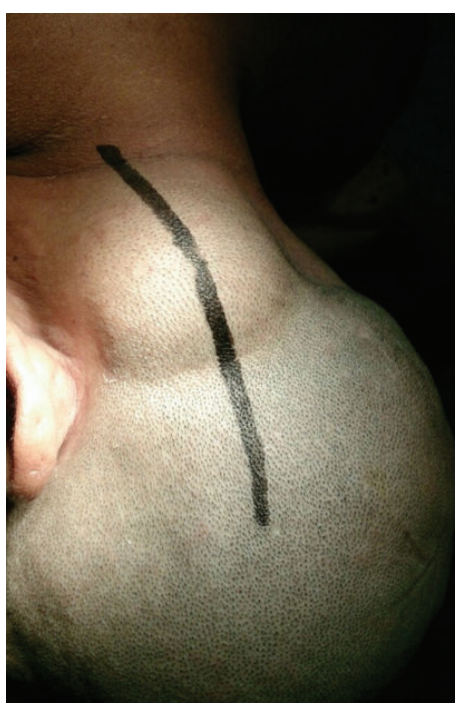

FIGURE 1: Image showing the extent of lesion and the planned surgical incision mark.

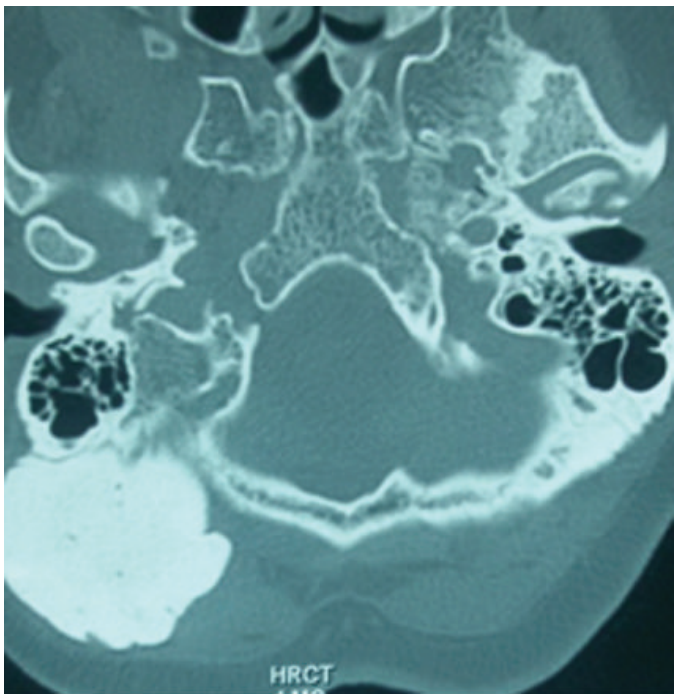

FIGURE 2: CT bone window showing the large lesion in the right suboccipital and adjacent mastoid region.

than $3 \mathrm{~cm}$ are termed giant osteomas [9]. They are also common in the frontoethmoidal region with above 40 cases reported in the literature $[10,11]$. Only few cases of giant osteomas involving the occipital region $[2,3]$, posterior skull base [12], and the atlas [4] have been reported in the literature so far.

Etiology of the entity includes trauma, previous surgery, radiotherapy, chronic infection, and hormonal factors [13]. They may be a reliable marker for early detection of carriers of Gardner syndrome [14]. They are mostly asymptomatic, but they can present with deformity, swelling, pain, deafness, and chronic discharge [15]. Computed tomography is the imaging modality of choice which demonstrates a rounded

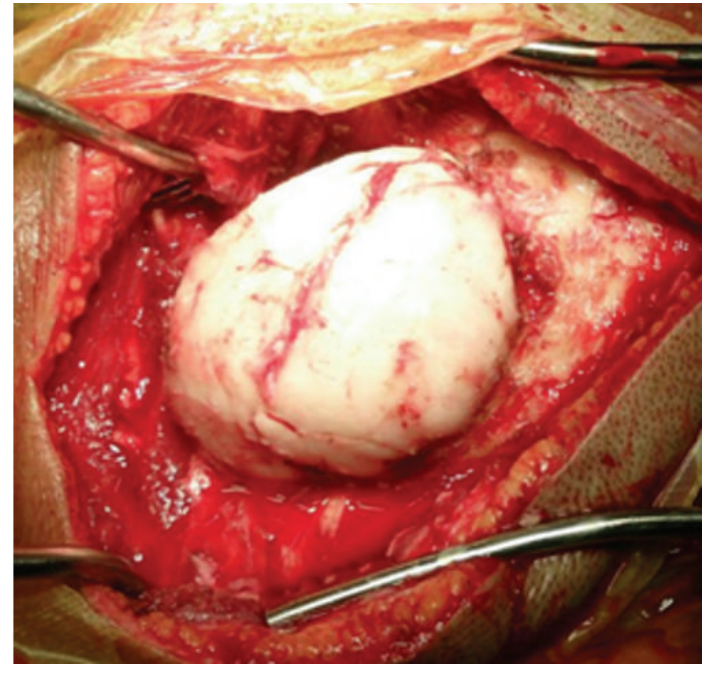

FIGURE 3: Intraoperative picture outlining the lesion.

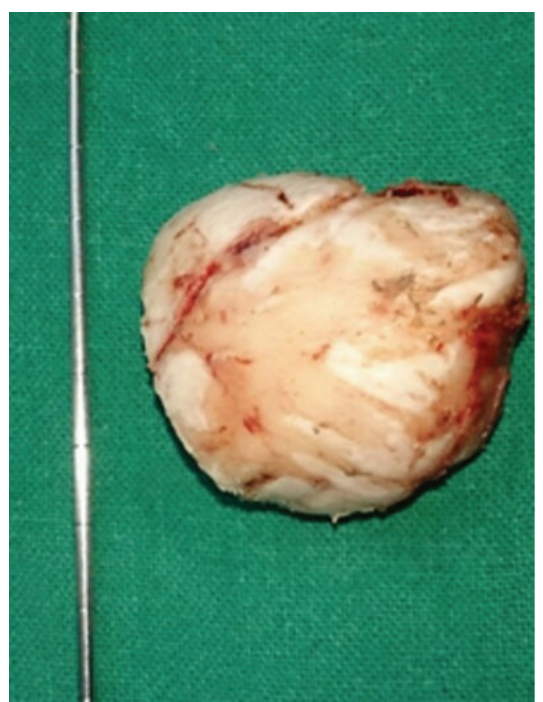

Figure 4: The excised bony lesion.

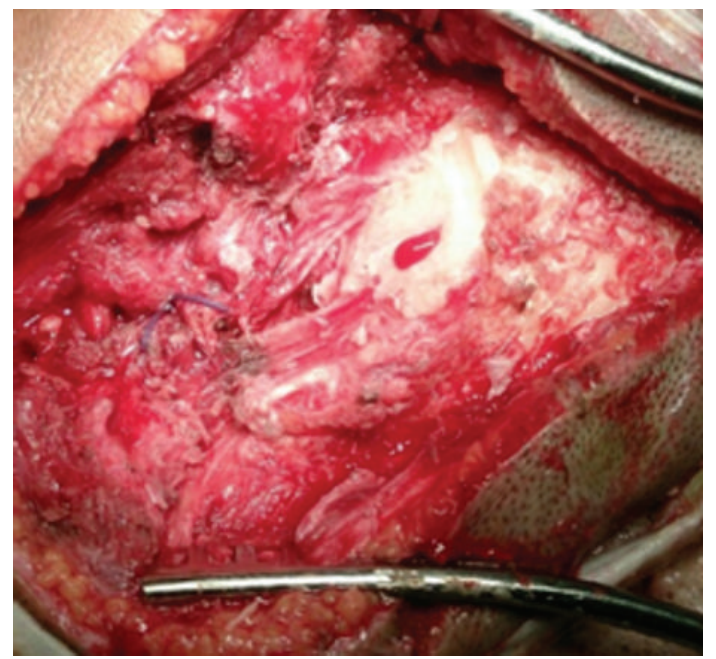

Figure 5: The calvarial base after excision of the bony tumor. 
bony lesion on the mastoid outer cortex having distinctive margins with sessile or pedunculate base $[16,17]$.

The main differential diagnosis includes osteosarcoma, osteoblastic metastasis, isolated eosinophilic granuloma, ossifying fibroma, Paget's disease, giant cell tumor, osteoid osteoma, hemangioma, calcified meningioma, and monostotic fibrous dysplasia [5, 18-21]. However, edges of these lesions are generally less distinct compared to the osteomas.

Osteomas are resected only if they are symptomatic or else for cosmetic reasons. The surgical target must be outlining normal cortical bone all around the lesion. Because these lesions are limited to the external cortex, finding a plane of cleavage between the osteoma and normal bone is not difficult [22]. If mastoid air cells are exposed, a cortical mastoidectomy should be done [23]. Partial excision is justified if there is an extension to either facial nerve, bony labyrinth, or the fallopian canal [24, 25]. In such invasive scenario, damage to the facial nerve, tearing of the sigmoid sinus, and postoperative auricular discharge may complicate the postoperative course [13].

Histologically, osteomas are composed of welldifferentiated, mature bone characterized by dense lamellae with organized Haversian canals. Histologically, there are three different subtypes: compact, spongiotic, and mixed [25].

The prognosis of the osteoma may be considered the best in terms of cosmetic and curative aspects provided complete excision is undertaken. Malignant transformation has not been reported yet [24]. The recurrence is also uncommon as only two cases have been reported so far [26].

In young patients with skull osteomas, complete workup needs to be done to rule out Gardner syndrome by screening for the concurrent presence of intestinal polyps, soft tissue tumors, and dental abnormalities [27].

\section{Conclusion}

Giant occipital osteomas have been rarely reported in the literature. Like giant osteomas in other locations of the skull, they can reach large volumes but are essentially benign and potentially curable by excision. Proper assessment of its extension especially when it is in the vicinity of the mastoid and the suboccipital regions is imperative to providing complete excision and limiting postoperative complications.

\section{Consent}

Both written and verbal consent for publication of images and clinical data related to this case were sought and obtained from the husband of the patient.

\section{Competing Interests}

The authors declare that there are no competing interests.

\section{Authors' Contributions}

Dr. Sunil Munakomi reviewed the literature, designed the study, and formatted the paper. Dr. Binod Bhattarai revised and edited and approved the final format.

\section{References}

[1] R. Meher, B. Gupta, I. Singh, and A. Raj, "Osteoma of occipital bone," Indian Journal of Surgery, vol. 66, no. 6, pp. 365-367, 2004.

[2] F. Erten, A. E. Hasturk, I. Pak, and O. Sokmen, "Giant occipital osteoid osteoma mimicking calcified meningioma," Neurosciences, vol. 16, no. 4, pp. 363-365, 2011.

[3] K. Nishitani, K. Okajima, and T. Tsuda, "A case of giant osteoma in the occipital bone," No Shinkei Geka, vol. 18, no. 10, pp. 947952, 1990 (Japanese).

[4] M. P. De Praeter, G. F. Dua, P. C. Seynaeve, D. G. Vermeersch, and R. L. Klaes, "Occipital pain in osteoid osteoma of the atlas. A report of two cases," Spine, vol. 24, no. 9, pp. 912-914, 1999.

[5] M. S. Ahmadi, M. Ahmadi, and A. Dehghan, "Osteoid osteoma presenting as a painful solitary skull lesion: a case report," Iranian Journal of Otorhinolaryngology, vol. 26, no. 75, pp. 115118, 2014.

[6] S. J. Park and Y. H. Kim, "A case of giant osteoma developed from the mastoid cortical bone," Korean Journal of Audiology, vol. 16, no. 2, pp. 95-98, 2012.

[7] U. P. Carlos, R. W. F. de carvalho, A. M. G. de Almeida, and N. D. Rafaela, "Mastoid osteoma. Consideration on two cases and literature review," International Archives of Otorhinolaryngology, vol. 13, pp. 350-353, 2009.

[8] M. Sente, R. Topolac, K. Peić-Gavran, and G. Aleksov, "Frontal sinus osteoma as a cause of purulent meningitis," Medicinski pregled, vol. 52, no. 3-5, pp. 169-172, 1999.

[9] Y. Izci, "Management of the large cranial osteoma: experience with 13 adult patients," Acta Neurochirurgica, vol. 147, no. 11, pp. 1151-1155, 2005.

[10] K.-J. Cheng, S.-Q. Wang, and L. Lin, "Giant osteomas of the ethmoid and frontal sinuses: clinical characteristics and review of the literature," Oncology Letters, vol. 5, no. 5, pp. 1724-1730, 2013.

[11] R. Vishwakarma, S. T. Joseph, K. B. Patel, and A. Sharma, "Giant frontal osteoma: case report with review of literature," Indian Journal of Otolaryngology and Head \& Neck Surgery, vol. 63, supplement 1, pp. 122-126, 2011.

[12] F. Layadi, K. Aniba, M. Lmejjati, A. Aït Elqadi, and S. Aït Benali, "Giant osteoid osteoma of the posterior skull base. A case report and literature review," Neurochirurgie, vol. 52, no. 2-3, part 1, pp. 128-132, 2006.

[13] A. K. Das and R. C. Kashyap, "Osteoma of the mastoid bone-a case report," Medical Journal Armed Forces India, vol. 61, no. 1, pp. 86-87, 2005.

[14] S. Panjwani, A. Bagewadi, V. Keluskar, and S. Arora, “Gardner's syndrome," Journal of Clinical Imaging Science, vol. 1, article 65, 2011.

[15] N. Guérin, E. Chauveau, M. Julien, J. M. Dumont, and G. Merignargues, "Osteoma of the mastoid bone: report of two cases," Revue de Laryngologie Otologie Rhinologie, vol. 117, no. 2, pp. 127-132, 1996.

[16] A. Gungor, H. Cincik, E. Poyrazoglu, O. Saglam, and H. Candan, "Mastoid osteomas: report of two cases," Otology and Neurotology, vol. 25, no. 2, pp. 95-97, 2004.

[17] M. El Fakiri, W. El Bakkouri, C. Halimi, A. Aït Mansour, and D. Ayache, "Mastoid osteoma: report of two cases," European Annals of Otorhinolaryngology, Head and Neck Diseases, vol.128, no. 5, pp. 266-268, 2011. 
[18] A. Greenspan, "Benign bone-forming lesions: osteoma, osteoid osteoma, and osteoblastoma: clinical, imaging, pathologic, and differential considerations," Skeletal Radiology, vol. 22, no. 7, pp. 485-500, 1993.

[19] A. Güngör, H. Cincik, E. Poyrazoglu, O. Saglam, and H. Candan, "Mastoid osteomas: report of two cases," Otology and Neurotology, vol. 25, no. 2, pp. 95-97, 2004.

[20] A. S. Kieffer, D. M. Long, N. S. Chou, G. A. King, and E. D. Cacayorin, "Tumors of the skull," in Neurological Surgery, J. R. Youmans, Ed., pp. 3599-3601, WB Saunders, Philadelphia, Pa, USA, 1990.

[21] J. S. Mehta, M. M. Sharr, and C. C. Penney, "Unusual radiological appearance of a skull osteoma," British Journal of Neurosurgery, vol. 13, no. 3, pp. 332-334, 1999.

[22] C. U. Pereira, J. D. B. C. Leão, A. D. Silva, P. R. M. Sousa, W. G. P. Soares, and M. B. O. Santos, "Osteoma craniano. Considerações sobre oito casos," Arquivos Brasileiros de Neurocirurgia, vol. 19, no. 4, pp. 170-173, 2000.

[23] A. Denia, F. Perez, R. R. Canalis, and M. D. Graham, "Extracanalicular osteomas of the temporal bone," Archives of Otolaryngology, vol. 105, no. 12, pp. 706-709, 1979.

[24] L. E. Probst, L. Shankar, and R. Fox, "Osteoma of the mastoid bone," Journal of Otolaryngology, vol. 20, no. 3, pp. 228-230, 1991.

[25] A. Ben-Yaakov, J. Wohlgelernter, and M. Gross, "Osteoma of the lateral semicircular canal," Acta Oto-Laryngologica, vol. 126, no. 9, pp. 1005-1007, 2006.

[26] J. F. Birrell, "Osteoma of the mastoid," Journal of the Royal College of Surgeons of Edinburgh, vol. 23, no. 5, pp. 305-309, 1978.

[27] D. Smud, G. Augustin, T. Kekez, E. Kinda, M. Majerovic, and Z. Jelincic, "Gardner's syndrome: genetic testing and colonoscopy are indicated in adolescents and young adults with cranial osteomas: a case report," World Journal of Gastroenterology, vol. 13, no. 28, pp. 3900-3903, 2007. 


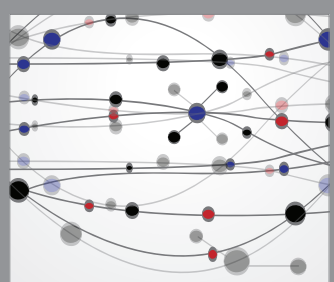

The Scientific World Journal
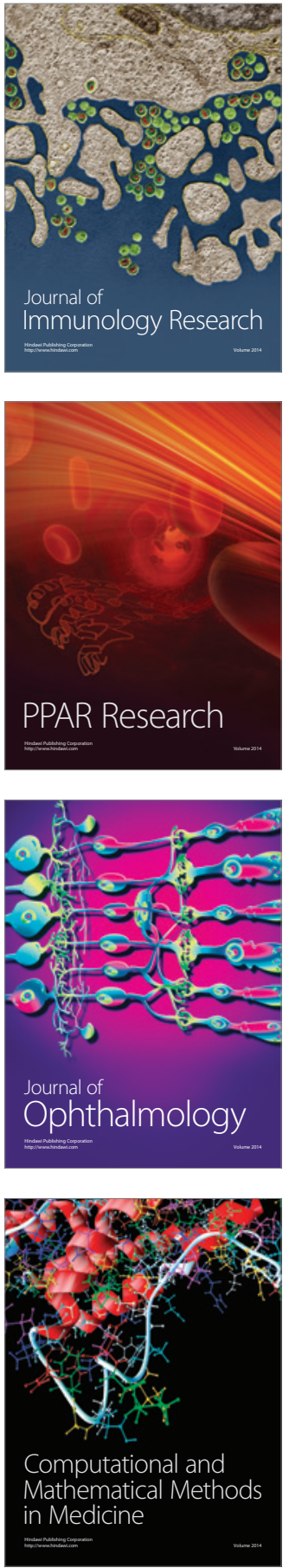

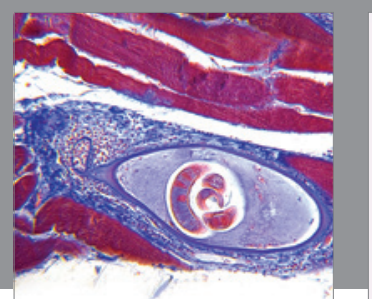

Gastroenterology Research and Practice

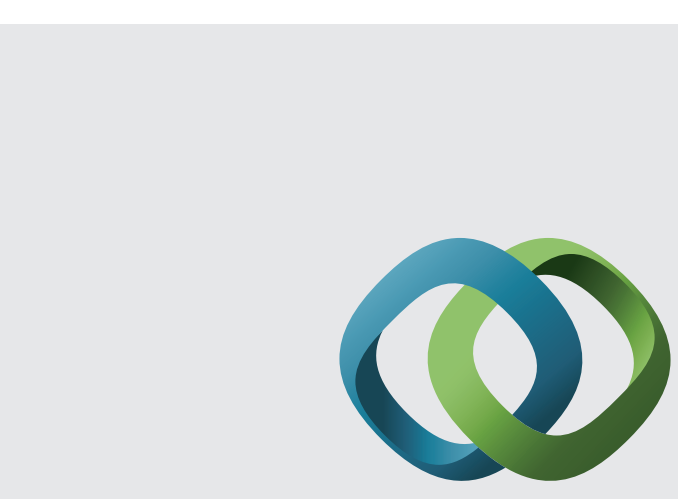

\section{Hindawi}

Submit your manuscripts at

http://www.hindawi.com
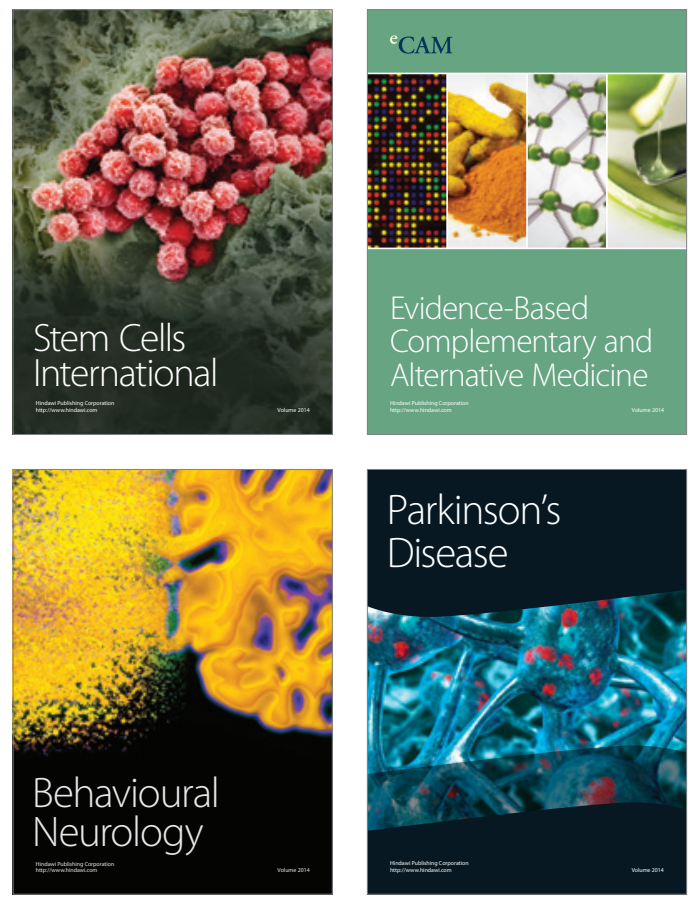
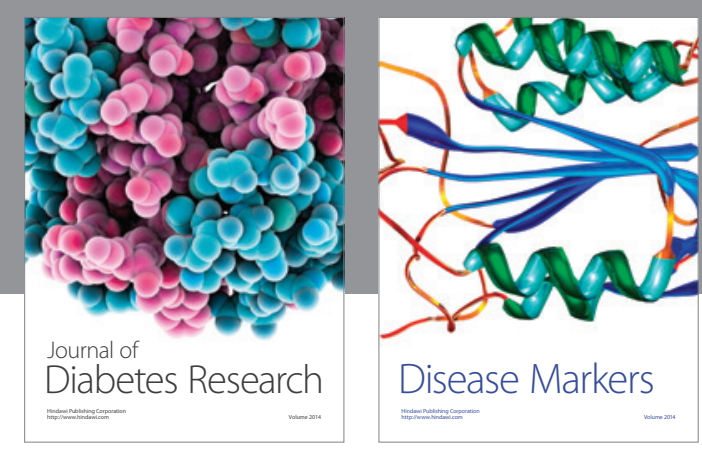

Disease Markers
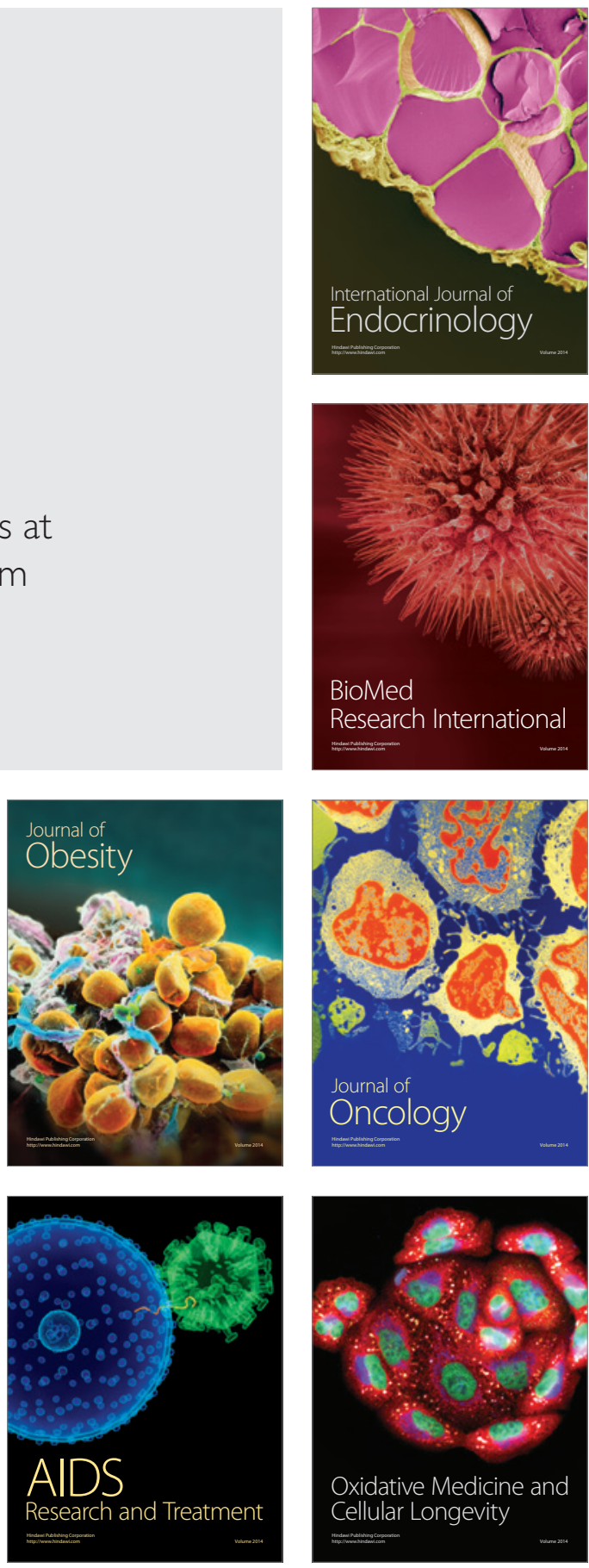